\title{
Traffic-related air pollution correlates with adult- onset asthma among never-smokers
}

\author{
N Künzlii, ${ }^{1,2,3,4}$ P-0 Bridevaux, ${ }^{5}$ L-J S Liu, ${ }^{6,7}$ R Garcia-Esteban, ${ }^{1,3,4}$ C Schindler, ${ }^{6}$ \\ M W Gerbase, ${ }^{5} \mathrm{~J}$ Sunyer, ${ }^{1,3,4,8}$ D Keidel, ${ }^{6}$ T Rochat, ${ }^{5}$ on behalf of SAPALDIA Team \\ (Swiss Cohort Study on Air Pollution and Lung Diseases in Adults)
}

\begin{abstract}
- Additional details are published online only at http:// thorax.bmj.com/content/vol64/ issue8

${ }^{1}$ Centre for Research in Environmental Epidemiology (CREAL), Barcelona, Spain:

${ }^{2}$ Catalan Institution for Research and Advanced Studies (ICREA), Spain; ${ }^{3}$ Municipal Institute of Medical Research (IMIM).

Barcelona, Spain; ${ }^{4}$ CIBER en Epidemiología y Salud Pública (CIBERESP), Spain; ${ }^{5}$ University Hospitals of Geneva, Geneva, Switzerland; ${ }^{6}$ Institute of Social and Preventive Medicine, University of Basel, Switzerland;

${ }^{7}$ University of Washington,

Seattle, Washington, USA;

${ }^{8}$ Universitat Pompeu Fabra

(UPF), Barcelona, Spain
\end{abstract}

Correspondence to:

Dr N Künzli, Center for Research in Environmental Epidemiology (CREAL), C Doctor Aiguader 88, 08003 Barcelona, Spain;

kuenzli@creal.cat

Received 28 October 2008 Accepted 18 March 2009 Published Online First 8 April 2009

\begin{abstract}
Background: Traffic-related pollution is associated with the onset of asthma in children. Its effect on adult-onset asthma is poorly investigated. The SAPALDIA cohort study was used to investigate associations between the 11 year change (1991-2002) in home outdoor traffic-related particulate matter up to $10 \mu \mathrm{m}$ in diameter $\left(\mathrm{TPM}_{10}\right)$ and the incidence of asthma.

Methods: Never-smokers without asthma at baseline aged 18-60 years in 1991 were eligible for inclusion in the study. Subjects reporting doctor-diagnosed asthma at follow-up were considered incident cases. TPM 10 at baseline and follow-up was predicted and interpolated to subjects' place of residence by dispersion models using emission and meteorological data. Cox proportional hazard models for time to asthma onset were adjusted lage, gender, baseline atopy, body mass index, bronchial reactivity, maternal allergies).
\end{abstract}

Results: Of 2725 never-smokers, 41 reported asthma onset in 2002. Home outdoor $\mathrm{TPM}_{10}$ concentrations improved during the interval (mean -0.6 ; range -9 to $+7.2 ;$ IQR $0.6 \mu \mathrm{g} / \mathrm{m}^{3}$ ). The incidence of asthma was associated with a change in $\mathrm{TPM}_{10}$. The hazard ratio (1.30; $95 \% \mathrm{Cl} 1.05$ to 1.61 ) per $1 \mu \mathrm{g} / \mathrm{m}^{3}$ change in $\mathrm{TPM}_{10}$ (IOR) was not sensitive to further adjustments (education, workplace exposure, passive smoking, parental asthma or allergies, random area effects, lung function or copollutants such as regional, secondary, total $\mathrm{PM}_{10}$ or proximity to busy roads).

Conclusion: The data suggest a role for traffic-related pollution in adult-onset asthma. Space, time and sourcespecific individual assignment of exposure to trafficrelated pollution is a key strength of SAPALDIA. It may explain why findings were statistically significant despite the limited number of new cases. As traffic-related pollution prevails, the finding may be of substantial public health relevance.

Currently prevailing levels of ambient air pollutants exacerbate asthma. Thus, asthma-related symptoms, emergency room visits and hospital admissions all increase-together with the need for asthma treatments - during periods with higher outdoor air pollution. ${ }^{12}$ A controversial question, though, is whether chronic exposure to ambient air pollution causes new onset of asthma. Earlier studies comparing the prevalence of asthma across communities with different levels of pollution did not support this notion. ${ }^{3}$ However, cross-community comparisons fail to characterise contrasts in exposure occurring within communities. The main reason for such small-scale contrasts is traffic. Related pollutants reach far higher concentrations on and along busy roads compared with locations 50-200 m away from traffic arteries. ${ }^{4}$ A recent review showed that living near traffic sources is associated with both onset and exacerbation of childhood asthma. ${ }^{2}$

The aetiology of asthma may well depend on the age of onset of the disease. ${ }^{5}$ However, adult-onset asthma has received less attention, and discussions centre mostly around smoking and occupational causes. ${ }^{67}$ Cohort studies indicate that onset of asthma among adults is not uncommon; for example, the Nurses Health Study reported approximately one new case of asthma per 1000 adults occurring every year. ${ }^{8}$ In the younger European Community Respiratory Health Survey (ECRHS), the incidence was 2.3 new cases per 1000 personyears. ${ }^{9}$ The first study suggesting an association between home outdoor nitrogen dioxide concentrations $\left(\mathrm{NO}_{2}\right)$, used as marker for traffic-related pollution, and adult-onset asthma has only recently been published. ${ }^{10}$ The results did not reach statistical significance. Most recently, ECRHS and its Nordic companion study RHINE observed very similar associations between the incidence of asthma and modelled $\mathrm{NO}_{2}$ concentrations. ${ }^{11}{ }^{12}$ ECHRS was based on a model with a rather limited spatial resolution $(1 \times 1 \mathrm{~km})$ available for the follow-up only, ${ }^{13}{ }^{14}$ while RHINE was based on air quality at baseline with no information about interval pollution.

We now use the Swiss Cohort Study on Air Pollution and Lung Diseases in Adults (SAPALDIA), a population-based cohort study initiated in 1991 and followed up 11 years later. Source-specific levels of pollution were spatially assigned to each participant and to the entire follow-up period. Recently, using this cohort, it was shown that an improvement in air quality is associated with an attenuated decline in lung function. ${ }^{15}$ The objective of this new analysis was to investigate whether individual-level change in exposure to local traffic-related pollutants correlated with adult-onset asthma. We focus the analysis on never-smokers. Tobacco smoke and ambient air pollution have hundreds of constituents in common, but concentrations in cigarette smoke are much higher so that, among smokers, exposure to these constituents is dominated by smoking, a well accepted cause of asthma.

\section{METHODS}

\section{Study design and population}

Selection of the study participants and methods of the cross-sectional study (SAPALDIA 1) and the 
Table 1 Description of study population: lifetime never-smokers with and without incident asthma at SAPALDIA 2

\begin{tabular}{|c|c|c|c|c|}
\hline & $\begin{array}{l}\text { No asthma } \\
(\mathrm{N}=2684)\end{array}$ & $\begin{array}{l}\text { New-onset } \\
\text { asthma } \\
\text { (N=41) }\end{array}$ & $\begin{array}{l}\text { Total } \\
(\mathrm{N}=2725)\end{array}$ & p Value $\dagger$ \\
\hline Age at baseline $\leqslant 40$ years (\%) & 48.55 & 63.41 & 48.77 & 0.059 \\
\hline Women (\%) & 61.36 & 63.41 & 61.39 & 0.789 \\
\hline $\begin{array}{l}\text { Bronchial hyperreactivity at baseline (missing, } \\
\mathrm{n}=506)(\%)\end{array}$ & 7.01 & 17.14 & 7.17 & 0.021 \\
\hline Atopy at baseline (missing, $n=244$ ) (\%) & 28.41 & 60.00 & 28.86 & $<0.001$ \\
\hline Maternal allergies at baseline (\%) & 15.22 & 7.50 & 15.10 & 0.176 \\
\hline $\mathrm{FEV}_{1}$ at baseline $\leqslant 85 \%$ predicted $(\%)$ & 2.61 & 2.44 & 2.61 & 0.946 \\
\hline Work exposure to dast/fumes at baseline (\%) & 29.65 & 37.50 & 29.76 & 0.281 \\
\hline $\begin{array}{l}\text { Environmental tobacco smoke at home at baseline } \\
\text { (\%) }\end{array}$ & 15.09 & 14.63 & 15.08 & 0.936 \\
\hline Age ending full-time education $\leqslant 20$ years $(\%)$ & 66.20 & 65.85 & 66.20 & 0.963 \\
\hline Main street within 20 m (SAPALDIA 1 address) (\%) & 18.83 & 17.07 & 18.81 & 0.775 \\
\hline Mean (SD) age at follow-up (years) & $50.83(12.25)$ & $45.35(11.58)$ & $50.74(12.26)$ & 0.005 \\
\hline Mean (SD) BMI at baseline & 23.50 (3.65) & $23.67(3.22)$ & 23.50 (3.64) & 0.583 \\
\hline Mean (SD) FEV 1 \%predicted at baseline & $123.11(24.93)$ & $116.17(17.60)$ & $123.00(24.85)$ & 0.120 \\
\hline Mean (SD) traffic $\mathrm{PM}_{10}$ at SAPALDIA 1 & $2.84(1.80)$ & $2.42(1.61)$ & $2.84(1.80)$ & 0.120 \\
\hline Mean (SD) traffic $\mathrm{PM}_{10}$ at SAPALDIA 2 & $2.25(1.43)$ & $2.17(1.43)$ & $2.25(1.43)$ & 0.126 \\
\hline Mean (SD) total PM $_{10}$ at SAPALDIA 1 & $27.68(10.03)$ & $26.46(10.32)$ & $27.66(10.04)$ & 0.393 \\
\hline Mean (SD) total $\mathrm{PM}_{10}$ at SAPALDIA 2 & $21.45(7.17)$ & $21.41(7.90)$ & $21.45(7.18)$ & 0.440 \\
\hline Mean $(S D)$ change in total $\mathrm{PM}_{10}$ & $-6.23(4.40)$ & $-5.05(5.02)$ & $-6.21(4.41)$ & 0.619 \\
\hline $\begin{array}{l}\text { Change in traffic } \mathrm{PM}_{10}\left(\mu \mathrm{g} / \mathrm{m}^{3}\right) \text { (main exposure } \\
\text { metric) }\end{array}$ & $-0.59(1.13)$ & $-0.25(1.40)$ & $-0.59(1.14)$ & \\
\hline 25th percentile & -0.80 & -0.61 & -0.80 & - \\
\hline 50th percentile & -0.39 & -0.30 & -0.39 & - \\
\hline 75th percentile & -0.21 & -0.11 & -0.21 & - \\
\hline Interquartile range & 0.59 & 0.50 & 0.59 & - \\
\hline
\end{tabular}

BMI, body mass index; $\mathrm{FEV}_{1}$, forced expiratory volume in $1 \mathrm{~s}$; $\mathrm{PM}_{10}$, particulate matter up to $10 \mu \mathrm{m}$ in diameter; SAPALDIA, Swiss Cohort Study on Air Pollution and Lung Diseases in Adults.

$\dagger p$ Value for $\chi^{2}$ test or Kruskal-Wallis test comparing the two groups.

follow-up study (SAPALDIA 2) have been described elsewhere. $^{16}{ }^{17}$ Random samples of adults (18-60 years) were recruited in 1990 using population registries in eight Swiss areas. Health examinations were conducted in 9651 adults

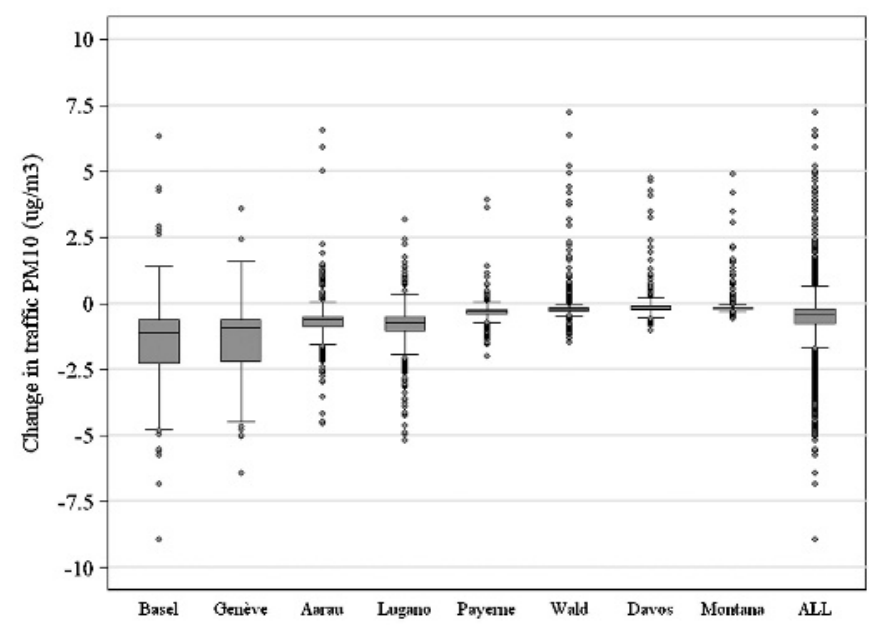

Figure 1 Distribution of the change in traffic-related individually assigned concentrations of particulate matter up to $10 \mu \mathrm{m}$ in diameter $\left(\mathrm{TPM}_{10}\right)$ by study area and for the total sample. The eight areas are ordered by the annual mean $\mathrm{TPM}_{10}$ at baseline. Negative changes indicate improvements in air quality. The reduction in $\mathrm{TPM}_{10}$ was on average larger in the most polluted areas (Basel and Geneva). Boxes show the median and quartiles (25th and 75th percentile) of the distribution. (mean age 40.6 years; 51\% women) in 1991 (SAPALDIA 1), with 8047 participants reassessed in 2002 (SAPALDIA 2). There were 5734 participants $(71.3 \%$ ) without asthma or spirometrydefined chronic obstructive pulmonary disease (COPD) at baseline, and with annual home outdoor concentrations of particulate matter up to $10 \mu \mathrm{m}$ in diameter $\left(\mathrm{PM}_{10}\right)$ available for both surveys (table 1 and fig 1 ). The 2725 never-smokers $(47.6 \%)$ are the sample used in this analysis. Ethical approval was obtained from the Swiss Academy of Medical Sciences and the regional ethics committees and via written informed consent from all participants.

\section{Air pollution exposure assessment}

The concentration of $\mathrm{PM}_{10}$ was used as a marker of air pollution. Details of the individual assignment of exposure are given in the online supplement. In brief, the 1990 and 2000 PolluMap dispersion model was used. ${ }^{18}$ Inputs were hourly meteorological and emission inventory data (industrial and commercial construction, household heating, agricultural and forestry activities, traffic emissions). ${ }^{18-20}$ Annual mean concentrations were derived from the hourly predictions for each $200 \times 200 \mathrm{~m}$ grid cell and each source. All residential addresses were linked to the models. Values between 1990 and 2000 were interpolated using the historical trends of central site measurements. ${ }^{18}$ Differences in the annual traffic-related home outdoor $\mathrm{PM}_{10}$ concentrations between the two SAPALDIA studies were used to estimate the change in exposure (with a negative change indicating improvements in air quality). Henceforth, we use the term $\mathrm{dTPM}_{10}$ for the difference in traffic-related $\mathrm{PM}_{10}$ and $\mathrm{TPM}_{10}$ for traffic-related $\mathrm{PM}_{10}$. The use of the interval exposure, 


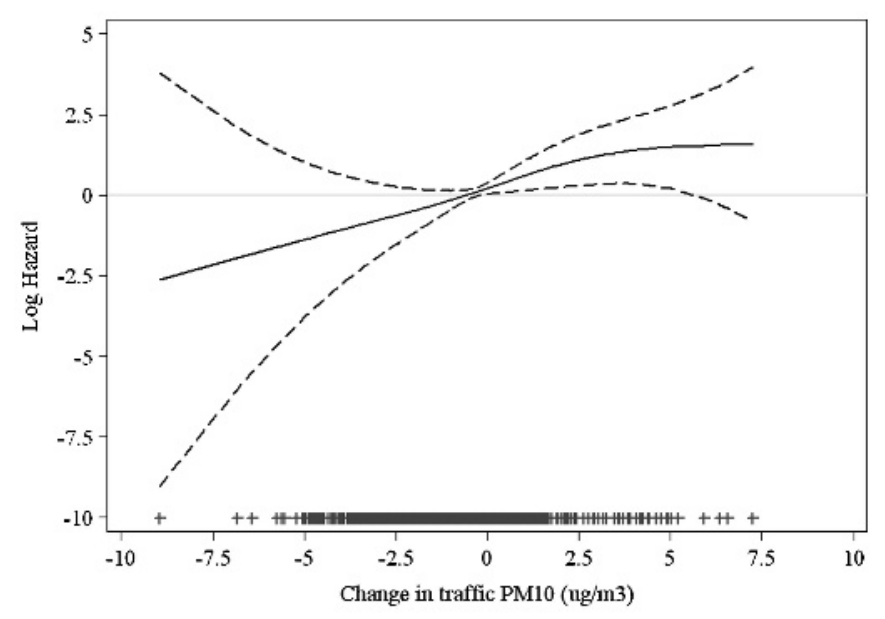

Figure 2 Association between change in traffic-related concentrations of particulate matter up to $10 \mu \mathrm{m}$ in diameter $\left(\mathrm{PM}_{10}\right)$ and adult-onset asthma (log hazard with 95\% confidence interval) among SAPALDIA never-smokers. Generalised additive model adjusted for age, sex, atopy at baseline, body mass index at baseline, bronchial hyperreactivity at baseline, maternal allergies. The symbols $(+)$ on the $x$-axis indicate observations.

defined as the cumulated mean concentration of home outdoor levels of $\mathrm{TPM}_{10}$ across the follow-up period, will be discussed. While our hypothesis is based on $\mathrm{TPM}_{10}$, we discuss the use of changes in regional, secondary and total $\mathrm{PM}_{10}$ as part of the sensitivity analyses. Analyses using proximity buffers (20, 50, $75,100,150 \mathrm{~m})$ as markers of exposure are discussed in the online supplement.

\section{Definition of asthma and covariates}

Asthma was defined as positive answers to both questions that are standard in many studies, namely "Have you ever had asthma?" and "Was this confirmed by a doctor?". ${ }^{16}{ }^{21}$ To define onset of doctor-diagnosed asthma, henceforth referred to as "asthma", those with asthma or COPD (forced expiratory volume in $1 \mathrm{~s} /$ forced vital capacity $\left.\left(\mathrm{FEV}_{1} / \mathrm{FVC}\right)<0.7\right)$ at baseline were excluded. Moreover, we excluded subjects without asthma at baseline who reported asthma at follow-up but indicated the year of onset to be prior to baseline. In sensitivity analyses we also ignored the latter restriction and, alternatively, made further restrictions at baseline, mainly requiring no asthma, no COPD and no bronchial hyperreactivity (BHR) based on the standard methacholine inhalation test. ${ }^{16} 22$

Detailed information about current, past and passive smoking, occupational exposure to dust and fumes and other risk factors was gathered through interview-administered questionnaires. ${ }^{21}$ Participants were classified as atopic if they developed a weal to one or more of the eight common inhalant allergens tested in the baseline skin prick test. ${ }^{16} 21$

\section{Statistical analysis}

Details are given in the online supplement. In brief, our main goal was to determine whether changes in traffic-related air quality were associated with new onset of asthma. We focus on the associations between the incidence of adult-onset asthma and $\mathrm{dTPM}_{10}$. Models using the highly correlated $\mathrm{TPM}_{10}$ at SAPALDIA 1 and SAPALDIA 2 as well as interval exposures are discussed in the online supplement.

Analyses of incidence were based on Cox proportional hazard regression models. Time to onset of asthma was measured in years from SAPALDIA 1 to the reported age of first attack, or to SAPALDIA 2 among those without incident asthma (in which case outcomes were treated as censored). Covariates preselected on prior knowledge were considered as potential confounders if associated with incident asthma at a $\mathrm{p}$ value $\leqslant 0.2$. These variables were retained in the multivariate model if $p$ values were $<0.1$ or if the coefficient of $\mathrm{dTPM}_{10}$ was modified by $10 \%$ or more upon their removal. For time-varying variables (body mass index (BMI), BHR, $\mathrm{FEV}_{1}$ ), we also considered the change between SAPALDIA 1 and 2 as potential confounders. Figure 2 was based on a non-parametric regression using Generalised Additive Models (GAM)

Sensitivity analyses consisted of both less and more parsimonious models, and analyses were also restricted to participants who always lived in the original SAPALDIA area. We also tested random effects of area lived in at baseline. The exploratory assessment of heterogeneity across predetermined subgroups (fig 3) has limited statistical power but may be of interest in comparison with future studies.

Analyses were conducted with the statistical software Stata/ SE 10.0. $p$ Values of $<0.05$ were considered statistically significant. Proportional hazard assumptions were tested but never violated for the air pollution exposure terms.

\section{RESULTS}

Table 1 describes the main covariates of the 2725 never-smokers without asthma or COPD at baseline, stratified by incident asthma status at follow-up. A total of 41 subjects $(1.5 \%)$ developed asthma during the 11 years of follow-up, corresponding to an incidence rate of 1.39 (95\% CI 1.02 to 1.88$)$ cases per 1000 person-years. New cases were on average younger and more likely to be atopic at baseline than non-asthmatic subjects. Baseline BHR was also more prevalent among incident cases. Non-participants are described in table S1 in the online supplement.

Traffic emissions were reduced by an average of $25 \%$ across all areas between 1990 and $2000 .^{18}$ The area mean of the $\mathrm{TPM}_{10}$ ranged between 0.9 and $5.4 \mu \mathrm{g} / \mathrm{m}^{3}$ and between 0.8 and $3.1 \mu \mathrm{g}$ $\mathrm{m}^{3}$ in SAPALDIA 1 and 2, respectively, accounting for $6-16 \%$ of the total $\mathrm{PM}_{10}$ concentrations across the study areas. $\mathrm{TPM}_{10}$ was highly variable within areas. The within-area coefficient of variation (CV) ranged from $15 \%$ to $36 \%$ while the spatial variation of total $\mathrm{PM}_{10}$ within each area was small (range of CV $2-10 \%)$.

The distribution of area-specific $\mathrm{dTPM}_{10}$ is presented in fig 1. Table S4 in the online supplement provides the related data for movers and non-movers. Study areas are ordered by the area mean level of $\mathrm{TPM}_{10}$ at baseline. Changes were largest in the more polluted areas. The overall mean dTPM $_{10}$ was $-0.59 \mu \mathrm{g} /$ $\mathrm{m}^{3}$, with a range from -8.95 to 7.24 and an interquartile range from -0.80 to -0.21 (table 1 ).

Table 2 shows the asthma incidence hazard ratios for a $1 \mu \mathrm{g} /$ $\mathrm{m}^{3}$ change (approximately IOR) in TPM 10 from several models. The hazard ratios were not sensitive to modelling assumptions. We observed a tendency toward stronger associations in multivariate models compared with the unadjusted model or the age- and sex-adjusted basic model (table 2).

Adjustment for area or the number of years lived at the baseline address did not affect the point estimates either. A stricter definition of "no asthma", excluding subjects with hyperreactive airways at baseline, reduced the population to 1846 subjects. However, associations with $\mathrm{dTPM}_{10}$ remained similar ( $\mathrm{HR}=1.27 ; 95 \%$ CI 1.01 to 1.61 per $\left.\mu \mathrm{g} / \mathrm{m}^{3} \mathrm{dTPM}_{10}\right)$. As shown in table 3 , adjustment for change in regional, secondary 
Figure 3 Association between incidence of asthma and change in trafficrelated concentrations of particulate matter up to $10 \mu \mathrm{m}$ in diameter $\left(\mathrm{PM}_{10}\right)$ among subgroups of never-smokers (models adjusted for age, sex, atopy at baseline, body mass index at baseline, bronchial hyperreactivity (BHR) at baseline, maternal allergies). Hazard ratios (HR) are presented per $1 \mu \mathrm{g} / \mathrm{m}^{3}$ difference in traffic-related $\mathrm{PM}_{10}$ with 95\% confidence intervals (Cl); $p$ value for interaction for parental allergies $=0.088$; all other interactions $p>0.1$.

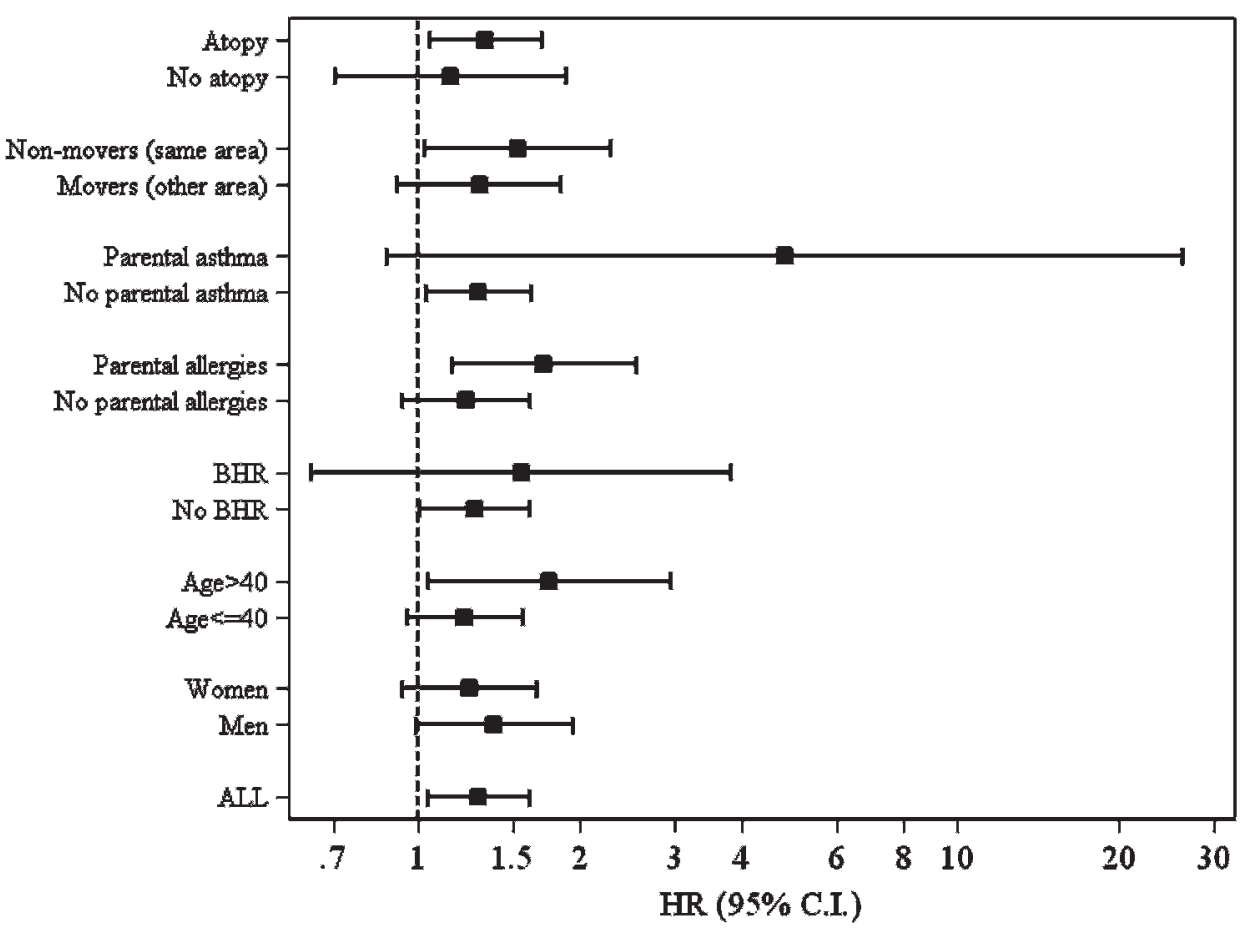

HR $(95 \%$ C.I. $)$ or total $\mathrm{PM}_{10}$ did not affect the point estimates for $\mathrm{dTPM}_{10}$ but inflated the confidence intervals yielding non-significant estimates. Hazard ratios of the 11-year change in these copollutants were instead very sensitive to adjustment by $\mathrm{dTPM}_{10}$. The null findings among smokers are shown in table S2 in the online supplement.

Residential proximity to busy roads was not associated with asthma. These results are discussed in the online supplement (including table S3).

Figure 2 shows the association between dTPM $_{10}$ and the log of the hazard ratio based on the main model of table 2 .

Area-specific estimates of $\mathrm{dTPM}_{10}$ reached statistical significance in only two communities (Wald and Payerne), with no indication of heterogeneity of associations across areas $(p=0.3)$. Hazard ratios among the subgroups explored for interaction are presented in fig 3. None of the apparent differences reached statistical significance for effect modification. Associations of $\mathrm{dTPM}_{10}$ with asthma onset appeared larger among those with parental allergies ( $p$ for heterogeneity $=0.088$ ). In general, estimates were larger among non-movers with the main model HR reaching 1.53 (95\% CI 1.02 to 2.28 ).

\section{DISCUSSION}

This study suggests that traffic-related air pollution has a role in the development of adult-onset asthma among never-smokers. These results are in line with numerous studies conducted in children. According to a recent review by Salam et al, ${ }^{2}$ evidence for a causal role of traffic-related air pollution on childhood asthma onset is strong and more recent studies further support the conclusions of Salam et al. ${ }^{23}$ The available individually

Table 2 Association between change in traffic-originated $\mathrm{PM}_{10}$ and asthma incidence among SAPALDIA never-smokers

\begin{tabular}{|c|c|c|c|}
\hline & $\mathbf{N}$ & HR $(95 \% \mathrm{CI})$ & p Value \\
\hline Unadjusted association & 2725 & $1.28(1.01$ to 1.61$)$ & 0.040 \\
\hline \multicolumn{4}{|l|}{ Adjusted for: } \\
\hline Age, gender & 2725 & $1.22(0.98$ to 1.51$)$ & 0.072 \\
\hline Age, gender, baseline atopy, BMI, BHR, maternal allergies (main model) & 2390 & $1.30(1.05$ to 1.61$)$ & 0.018 \\
\hline Main model + paternal asthma & 2303 & $1.34(1.08$ to 1.67$)$ & 0.007 \\
\hline Main model + random effect for study area & 2390 & $1.32(1.06$ to 1.65$)$ & 0.013 \\
\hline Main model + education and work exposure & 2368 & $1.30(1.05$ to 1.61$)$ & 0.018 \\
\hline Main model $+\mathrm{FEV}_{1}$ at baseline (\% predicted) & 2390 & $1.30(1.05$ to 1.61$)$ & 0.015 \\
\hline Main model + environmental tobacco smoke at baseline & 2390 & $1.30(1.05$ to 1.61$)$ & 0.018 \\
\hline Main model + years lived at SAPALDIA 2 address & 2380 & $1.30(1.03$ to 1.63$)$ & 0.025 \\
\hline Main model, non-movers only (same residence SAPALDIA 1 and 2) & 2022 & $1.53(1.02$ to 2.28$)$ & 0.039 \\
\hline Main model, but loose definition of "new asthma"* & 2409 & $1.17(0.96$ to 1.42$)$ & 0.114 \\
\hline
\end{tabular}

$\mathrm{BHR}$, bronchial hyperreactivity; $\mathrm{BMI}$, body mass index; $\mathrm{Cl}$, confidence interval; FEV 1 , forced expiratory volume in $1 \mathrm{~s}$; $\mathrm{HR}$, hazard ratio; PM $_{10}$, particulate matter up to $10 \mu \mathrm{m}$ in diameter; SAPALDIA, Swiss Cohort Study on Air Pollution and Lung Diseases in Adults.

Hazard ratios (HR) are given per $1 \mu \mathrm{g} / \mathrm{m}^{3} \mathrm{dTPM}_{10}$ and presented for several models. The first two models include all 41 new cases of asthma; the others are based on 38 new cases due to some missing data in the covariates.

* Includes newly reported asthma at SAPALDIA 2 but age of onset reported as before SAPALDIA 1; age of onset was set to 0.1 years. 
Table 3 Association between incidence of asthma and change in traffic-related $\mathrm{PM}_{10}$ and other $\mathrm{PM}_{10}$ variables among SAPALDIA never-smokers (two-pollutant models)

\begin{tabular}{llll}
\hline & & \multicolumn{2}{l}{ Two-pollutant model } \\
\cline { 3 - 4 } Co-pollutant & Single-pollutant model & HR for $\mathbf{d T P M} \mathbf{M}_{\mathbf{1 0}}$ & HR for co-pollutant \\
\hline Change in traffic-related $\mathrm{PM}_{10}\left(\mathrm{dTPM}_{10}\right)$ & $1.30(1.05$ to 1.61$)$ & $1.30(1.05$ to 1.61$)$ & $\mathrm{N} / \mathrm{A}$ \\
Change in regional $\mathrm{PM}_{10}$ & $1.10(0.94$ to 1.30$)$ & $1.28(1.00$ to 1.64$)$ & $1.02(0.86$ to 1.21$)$ \\
Change in secondary $\mathrm{PM}_{10}$ & $1.44(0.89$ to 2.33$)$ & $1.30(0.98$ to 1.71$)$ & $1.00(0.53$ to 1.92$)$ \\
Change in total $\mathrm{PM}_{10}$ & $1.07(1.00$ to 1.14$)$ & $1.22(0.88$ to 1.71$)$ & $1.02(0.93$ to 1.13$)$ \\
Level of traffic-related $\mathrm{PM}_{10}$ at SAPALDIA 1 & $0.80(0.64$ to 1.00$)$ & $1.22(0.93$ to 1.59$)$ & 0.87 (0.68 to 1.11$)$ \\
\hline
\end{tabular}

$\mathrm{PM}_{10}$, particulate matter up to $10 \mu \mathrm{m}$ in diameter.

Hazard ratios (HR) and $95 \% \mathrm{Cl}$ are given per $1 \mu \mathrm{g} / \mathrm{m}^{3}$ and based on single-pollutant and two-pollutant models, adjusted for age, gender, baseline atopy, body mass index, bronchial hyperreactivity, maternal allergies (main model of table 2). All models include 2390 subjects and 34 new cases of asthma.

Total $\mathrm{PM}_{10}$ is the sum of all $\mathrm{PM}_{10}$ and thus includes traffic-related $\mathrm{PM}_{10}$.

assigned long-term characterisation of home outdoor pollution offered the unique opportunity to investigate how the change in traffic-related air quality affected adult-onset asthma. SAPALDIA has previously shown that improvement in air quality is associated with an attenuation in the decline of pulmonary function. ${ }^{15}$ Our novel results suggest that a decrease in air pollution is also paralleled by a reduced risk of developing asthma as an adult, or an increase in pollution correlates with a larger number of cases of adult-onset asthma.

The results need to be put in the context of several strengths and limitations. We first address challenges related to air pollution exposure assessment and then discuss the interpretation of the health outcome.

We believe that our ability of space, time and source-specific assignments of individual exposure is not only a strength but most likely a condition for successfully investigating the asthmaonset hypothesis. Our primary exposure term was the change in $\mathrm{TPM}_{10}$. Air quality improved during follow-up, but more so in the more polluted areas, leading to a negative correlation between baseline $\mathrm{TPM}_{10}$ and its change (dTPM10) $(\mathrm{r}=-0.76)$. Interval exposure correlated negatively with the change in $\mathrm{TPM}_{10}$ as well $(\mathrm{r}=-0.59)$. Thus, neither baseline exposure nor air quality at follow-up or interval exposure would capture the dynamic of a subject's exposure history. The only adequate alternative approach to our analysis would be the use of the interval exposure with adjustment for baseline $\mathrm{TPM}_{10}$, which corresponds conceptually and mathematically to our use of the change in $\mathrm{TPM}_{10}$. While this strategy gave similar point estimates (table 3), the collinearity between baseline $\mathrm{TPM}_{10}$ and interval TPM 10 greatly reduces precision in the estimation, underscoring the advantage of temporally resolved individual assignment of change in exposures.

The needs for accurate spatial and source-specific assignment of exposure are interrelated challenges for a successful investigation of the asthma hypothesis. Contrasts in subjects' exposure to air pollutants originate to a large extent from spatial heterogeneity in air quality within cities. These contrasts are primarily driven by traffic-originated pollutants, which can easily increase 5-10 times in concentration along the traffic arteries while decreasing to "urban background" concentrations within 200 m of such roads. ${ }^{4}{ }^{24}$ Thus, it is important to identify the exact residential location and to model traffic-specific markers of air pollution that reflect local spatial patterns. Our outdoor exposure model used source-specific emission inventories and estimated concentrations with a spatial resolution of $200 \times 200 \mathrm{~m}^{18}$ Models of some tail-pipe constituents may be improved with higher resolution. In this case, our estimates are likely to be biased to the null. Like other studies, we also ignored time at work or commuting. This misclassification may attenuate estimates, but we expect little bias as home outdoor remains the most important determinant of personal exposure to pollutants of outdoor origin. ${ }^{25}$

$\mathrm{TPM}_{10}$ ought to be considered a proxy for traffic-related primary pollutants rather than the culprit pollutant per se. Spatial distributions of other biologically relevant traffic-related toxicants (such as $\mathrm{PM}_{2.5}$, ultrafine particles, polycyclic aromatic hydrocarbons or redox active metals contained on fine PM) were not modelled separately and their correlation with $\mathrm{TPM}_{10}$ is not known. It may, however, be that what we label as "TPM 10 " captures in part also the spatial distribution in the exposure to ultrafine particles or other traffic-related constituents. Other markers of local traffic-related pollutants or PM compositions may result in different effect scales.

In contrast to several studies conducted in children, residential proximity to busy roads was not associated with asthma onset in our study. The limitation of such markers in a longitudinal study is discussed in the online supplement.

Point estimates were higher among subjects with better exposure assessment, namely those who never moved. Associations of asthma onset with $\mathrm{PM}_{10}$ from other sources were not only smaller but substantially decreased with adjustment for $\mathrm{dTPM}_{10}$ (eg, $\mathrm{PM}_{10}$ at baseline in table 3; other data not shown). In line with the findings in children, this observation further underscores the relevance of traffic-related versus urban background pollution in the development of asthma.

As emphasised by Eder et al, asthma is a syndrome rather than one disease, and various phenotypes of "asthma" may have different risk patterns. ${ }^{1}$ Our abilities to specify asthma phenotypes were limited as we relied on reported doctordiagnosed asthma, as used in many epidemiological studies. This precludes a more detailed assessment of phenotypes and the clinical distinction between asthma and COPD. The latter were excluded from our baseline population and the analyses are restricted to non-smokers, so the impact of misclassified diagnoses may be rather marginal in this analysis.

However, a major related problem is the definition of "onset of asthma". The distribution of time to onset varied substantially (see online table S5), and many reported onset of asthma prior to SAPALDIA 1 but did not report asthma at baseline. If we include those "loosely defined" new cases of asthma, associations remained positive but no longer statistically significant (see online table S6). Given the uncertainties related to the time of onset, the change in $\mathrm{TPM}_{10}$ was derived as the 
difference between SAPALDIA 1 and 2. The theoretically more appealing definition of the exposure window until asthma onset is discussed in the online supplement. These attenuated and non-significant findings must be interpreted with caution.

The identification of susceptible subgroups is of both public health and biological relevance. Given the limited number of new cases, we can only speculate about the meaning of the patterns shown in fig 3 . Taken at face value, the results would indicate that those with an inherently higher baseline risk for asthma due to atopy, BHR or parental asthma are more strongly affected by traffic-originated pollution. However, none of the interactions was statistically significant, which may reflect random variation. Modig et al reported higher risks among atopic subjects. ${ }^{10}$

The onset of asthma among smokers - another group with an inherently higher incidence of asthma-was not associated with $\mathrm{TPM}_{10}$ (see table S2 in the online supplement). If similar combustion-related constituents and immunological mechanisms were involved in asthma onset due to both smoking and traffic-related pollution, the contribution of the latter exposure may be marginal among smokers, resulting in null findings for $\mathrm{TPM}_{10}$.

The study by Modig et al was the first to use a marker of local traffic-related pollution (namely $\mathrm{NO}_{2}$ ) to investigate the asthma-onset hypothesis in adults. While their findings are in line with our results, the correlations were not statistically significant in the Swedish case-control study $(\mathrm{N}=2 \times 203) .{ }^{10}$ It is also of note that traffic-related $\mathrm{PM}_{10}$ at SAPALDIA 2 was not associated with asthma onset. Since the Swedish study was based on cases and controls recruited from only one city (77 000 inhabitants), the subjects may all have experienced the same (unknown) temporal trends in exposure. One may therefore expect that "current exposure" adequately ranked people's current, past as well as cumulative exposure. This assumption does not hold for SAPALDIA, which may explain the discrepancy between our results and those from the first Swedish study. In ECRHS the incidence of asthma also correlated significantly with home outdoor $\mathrm{NO}_{2}$ concentrations at follow-up, derived from an emission-based model. ${ }^{11}$ As in the first Swedish study, assignment of traffic-related exposure was done only for the address at follow-up as baseline air quality data were not available, ${ }^{13}$ so the positive results contrast with the null findings seen in our study if exposure at SAPALDIA 2 was used. It is not known whether air quality changes followed similar patterns for all participants across the 21 ECRHS centres, but follow-up in ECRHS was on average a few years shorter. The most recent Swedish study (2009) reported strikingly similar results to ECRHS, but was based on an $\mathrm{NO}_{2}$ dispersion model of high resolution $(50 \times 50 \mathrm{~m}) .{ }^{12}$ Our use of $\mathrm{TPM}_{10}$ precludes a quantitative comparison of risk estimates. Again, in contrast to our study, the Swedish study defines baseline exposure only. Spatial contrasts and changes may be less correlated in this study with shorter follow-up (8.3 years) and only three urban areas.

While the Seventh Day Adventist study (AHSMOG) reported an association between the incidence of asthma and ozone in men, as well as non-significant associations with particulate matter during the follow-up initiated in the late 1970s, local traffic-related pollution was not characterised. ${ }^{16}{ }^{21}$ Time, location and population characteristics differ substantially between AHSMOG and SAPALDIA, limiting formal comparisons.

Biases are not a plausible explanation for our positive findings. Point estimates were neither sensitive to model specification nor to adjustment for fixed and time-varying determinants of asthma incidence nor study area (fixed or random effect). It appears unlikely that some uncontrolled factor was a strong enough risk for asthma onset and sufficiently correlated with dTPM 10 to confound our estimates. To avoid multiple comparisons we a priori restricted the main analyses on one single marker of exposure-namely, trafficrelated particles. Despite small numbers of new cases, associations were clearly statistically significant in several models and thus are unlikely to be explained by chance alone.

The consistency between our findings and observations made in children suggests that similar mechanisms may be involved both in early-life asthma and adult-onset asthma. Many of the traffic-originated pollutants have strong redox cycling capacity. $^{26-28}$ This results in oxidative stress and both local as well as systemic inflammation, which are considered key pathways in the development of asthma. ${ }^{26}{ }^{29}$ Experimental studies confirm an adverse role in IgE-mediated allergic responses which may play a role in asthma development among atopic subjects. ${ }^{30}$ Our data suggest the latter to be more strongly affected by trafficrelated pollution. Respective findings in children are not consistent. ${ }^{2}$ This inconsistency may suggest different pathways being involved in childhood and adult-onset asthma among those exposed to traffic-related pollution. Future studies on adult-onset asthma may investigate the interaction of trafficoriginated pollutants with genetic variants to elucidate the mechanisms involved in the observed associations.

In summary, the ability to assign space, time and sourcespecific exposure to traffic-related pollution to each individual is a strong feature of SAPALDIA. In line with numerous studies conducted in children, the findings suggest that traffic-related local pollutants contribute to asthma development and, even more importantly, that reductions in these pollutants decrease asthma risks as well. Given the widespread exposure to traffic pollution, we recommend studies to investigate the mechanisms of adult-onset asthma and identify the most susceptible subjects. Studies with a much larger sample size of asthma cases would greatly attenuate all the limitations faced in this study.

Acknowledgements: The SAPALDIA team (as of December 2008) including the authors was responsible for the study. Letters in parentheses are defined as follows: a, allergology; c, cardiology; cc, clinical chemistry; e, epidemiology; exp, exposure; g, genetic and molecular biology; m, meteorology; p, pneumology; s, statistics. Study directorate: T Rochat (p), U Ackermann-Liebrich (e), J M Gaspoz (c), P Leuenberger (p), L J S Liu (exp), N M Probst Hensch (e/g), C Schindler (s). Scientific team: J C Barthélémy (c), W Berger (g), R Bettschart (p), A Bircher (a), G Bolognini (p), 0 Brändli (p), M Brutsche (p), L Burdet (p), M Frey (p), M W Gerbase (p), D Gold (e/c/p), W Karrer (p), R Keller (p), B Knöpfli (p), N Künzli (e/exp), U Neu (exp), L Nicod (p), M Pons (p), E Russi (p), P Schmid-Grendelmeyer (a), J Schwartz (e), P Straehl (exp), J M Tschopp (p), A von Eckardstein (cc), J P Zellweger (p), E Zemp Stutz (e).

Scientific team at coordinating centres: P O Bridevaux (p), I Curjuric (e), J Dratva (e), D Felber Dietrich (c), A Gemperli (s), D Keidel (s), M Imboden (g).

Funding: Swiss National Science Foundation (grants no 4026-28099, 3347CO108796, 3247B0-104283, 3247B0-104288, 3247B0-104284, 32-65896.01, 3259302.99, 32-52720.97, 32-4253.94); Federal Office for Forest, Environment and Landscape; Federal Office of Public Health; Federal Office of Roads and Transport; canton's government of Aargau, Basel-Stadt, Basel-Land, Geneva, Luzern, Ticino, Zurich; Swiss Lung League; canton's Lung League of Basel Stadt/Basel Landschaft, Geneva, Ticino and Zurich; Centre for Research in Environmental Epidemiology (CREAL), Barcelona, Spain; Catalan Institution for Research and Advanced Studies (ICREA), Barcelona, Spain. None of the funding sources had a role in the study design, data collection, analysis and interpretation of the data.

Competing interests: None.

Ethics approval: Ethical approval was obtained from the Swiss Academy of Medical Sciences and the regional ethics committees and written informed consent was obtained from all participants. 


\section{REFERENCES}

1. Eder W, Ege MJ, von Mutius E. The asthma epidemic. N Engl J Med 2006;355:2226-35

2. Salam MT, Islam T, Gilliland FD. Recent evidence for adverse effects of residential proximity to traffic sources on asthma. Curr Opin Pulm Med 2008;14:3-8.

3. Brunekreef B, Holgate ST. Air pollution and health. Lancet 2002;360:1233-42.

4. Zhou Y, Levy Jl. Factors influencing the spatial extent of mobile source air pollution impacts: a meta-analysis. BMC Public Health 2007:7:89.

5. Metsala J, Kilkkinen A, Kaila M, et al. Perinatal factors and the risk of asthma in childhood - a population-based register study in Finland. Am J Epidemiol 2008;168:170-8.

6. Jaakkola MS, Jaakkola JJ. Office work exposures and adult-onset asthma. Environ Health Perspect 2007:115:1007-11.

7. Le Moual N, Kauffmann F, Eisen EA, et al. The healthy worker effect in asthma: work may cause asthma, but asthma may also influence work. Am J Respir Crit Care Med 2008:177:4-10.

8. Barr RG, Wentowski CC, Curhan GC, et al. Prospective study of acetaminophen use and newly diagnosed asthma among women. Am J Respir Crit Care Med 2004;169:836-41.

9. Zock JP, Plana E, Jarvis D, et al. The use of household cleaning sprays and adult asthma: an international longitudinal study. Am J Respir Crit Care Med 2007; 176:735-41.

10. Modig L, Jarvholm B, Ronnmark E, et al. Vehicle exhaust exposure in an incident case-control study of adult asthma. Eur Respir J 2006;28:75-81.

11. Jacquemin $\mathbf{B}$, Sunyer J, Forsberg $\mathrm{B}$, et al. Home outdoor $\mathrm{NO}_{2}$ and new onset of selfreported asthma in adults. Epidemiology 2009;20:119-26.

12. Modig L, Toren K, Janson C, et al. Vehicle exhaust outside the home and onset of asthma among adults. Eur Respir J 2009 Feb 27 [Epub ahead of print].

13. Hazenkamp-von Arx ME, Gotschi T, Ackermann-Liebrich U, et al. PM2.5 and N02 assessment in 21 European study centres of ECRHS II: annual means and seasonal differences*1. Atmos Environ 2004;38:1943-53.

14. Beelen R, Hoek G, Pebesma E, et al. Mapping of background air pollution at a fine spatial scale across the European Union. Sci Total Environ 2009;407:1852-67.

15. Downs SH, Schindler C, Liu LJ, et al. Reduced exposure to PM10 and attenuated age-related decline in lung function. N Engl J Med 2007;357:2338-47.

16. Martin BW, Ackermann-Liebrich U, Leuenberger $\mathrm{P}$, et al. SAPALDIA: methods and participation in the cross-sectional part of the Swiss Study on Air Pollution and Lung Diseases in Adults. Soz Praventivmed 1997;42:67-84.
17. Ackermann-Liebrich $\mathbf{U}$, Kuna-Dibbert B, Probst-Hensch NM, et al. Follow-up of the Swiss Cohort study on Air Pollution and Lung Diseases in Adults (SAPALDIA 2) 1991 2003: methods and characterisation of participants. Soz Praventivmed 2005;50:24563.

18. Liu L-JS, Curjuric I, Keidel D, et al. Characterisation of source-specific air pollution exposure for a large population-based Swiss cohort (SAPALDIA). Environ Health Perspect 2007:115:1638-45.

19. Bundesamt für Umwelt, Wald und Landschaft (BUWAL). Modelling of PM10 and PM2.5 ambient concentrations in Switzerland 2000 and 2010. Schriftenreihe Umwelt 2003; Nr 169.

20. Bundesamt für Umwelt, Wald und Landschaft (BUWAL). Modellierung der PM10-Belastung in der Schweiz. Schriftenreihe Umwelt 1999;Nr 310.

21. Burney PG, Luczynska C, Chinn S, et al. The European Community Respiratory Health Survey. Eur Respir J 1994;7:954-60.

22. Chinn S, Burney $\mathrm{P}$, Jarvis $\mathrm{D}$, et al. Variation in bronchial responsiveness in the European Community Respiratory Health Survey (ECRHS). Eur Respir J 1997; 10:2495-501.

23. Jerrett M, Shankardass K, Berhane K, et al. Traffic-related air pollution and asthma onset in children: a prospective cohort study with individual exposure measurement. Environ Health Perspect 2008;116:1433-8.

24. Morawska LR, Ristovski Z, Jayaratne Z, et al. Ambient nano and ultrafine particles from motor vehicle emissions: characteristics, ambient processing and implications on human exposure. Atmos Environ 2008:42:8113-38.

25. Rojas-Bracho L, Suh HH, Koutrakis P. Relationships among personal, indoor, and outdoor fine and coarse particle concentrations for individuals with COPD. J Expo Anal Environ Epidemiol 2000:10:294-306.

26. Nel A. Air pollution-related illness: effects of particles. Science 2005;308:804-6.

27. Nel AE, Diaz-Sanchez D, Li N. The role of particulate pollutants in pulmonary inflammation and asthma: evidence for the involvement of organic chemicals and oxidative stress. Curr Opin Pulm Med 2001;7:20-6.

28. Künzli N, Mudway IS, Gotschi T, et al. Comparison of oxidative properties, light absorbance, total and elemental mass concentration of ambient PM2.5 collected at 20 European sites. Environ Health Perspect 2006;114:684-90.

29. Gilliland FD, McConnell R, Peters J, et al. A theoretical basis for investigating ambient air pollution and children's respiratory health. Environ Health Perspect 1999;107(Suppl 3):403-7.

30. Gilliland FD, Li YF, Saxon A et al. Effect of glutathione-S-transferase M1 and P1 genotypes on xenobiotic enhancement of allergic responses: randomised, placebocontrolled crossover study. Lancet 2004;363:119.

\section{Take advantage of BMJ Journals' remarkable catalogue of titles with Related Collections}

No busy professional has time to browse through all pertinent journals to find relevant articles, but with Related Collections you no longer have to. Follow the "Related Collections" link from any article and use the "Show Collections from other Journals" to expand your search across all BMJ Journals. Or simply follow the "Browse by topic" link on the home page. By setting up your own collections and receiving email alerts every time an article is added to your chosen area, you can build up your own significant body of knowledge. 